\title{
The Scope and Needs of Medical Research*
}

\section{By Sir Walter M. Fletcher, K.B.E., C.B., F.R.S.}

$\mathrm{T}$ HE phrase 'medical research' covers an immensely wide field of scientific activity in which workers of many different kinds are occupied. It is concerned directly and indirectly with the welfare of the bodies and minds of human beings, and if properly treated it must be a subject of the first interest to any human audience. The word 'medical' in this relation is likely to mislead. Strictly it refers only to the healing of disease, and it calls to our minds at once a vision of doctors at the bedside and of their drugs or implements. Yet as we use it here it has a scope, not only in the work of original investigation but also in preparing its results for practical application, which is indefinitely wider than that of the healing profession as such.

I can give an actual definition of the real scope of medical research in formal terms. It is a formula which has been adopted by His Majesty's Government to define the field of medical research work to which an annual Parliamentary grant-in-aid is made, and it is in these terms: "Medical research deals with the proper development and the right use of the human body in all conditions of activity and environment, as well as with its protection from disease and accident, and its repair".

Let us take each phrase of the definition in turn. The development of the human body: here we have to consider both nature and nurture, both inheritance and nutrition. Dangerous as it is in scientific studies to separate these sharply in our minds, as is so often done, each, nevertheless, is served by a special scientific discipline. One is served by the science of genetics and the other by the science of nutrition.

The science of genetics is still in its first infancy. By an easy effort of imagination we can form almost illimitable hopes of betterment in body and mind that fuller knowledge in this subject may hold out to the human race. Dreams of this are so attractive and may be so vivid as to tempt us to propose short cuts to make them real. Hasty practical proposals made in the name of what is called 'eugenics' are put forward. Many of these are based on obviously false assumptions, as, for example, that particular parts of the community are not desirable breeding stock, merely because at present they are inadequately fed; or, again, that the qualities which make many men rich are the qualities which we should desire to multiply in our race. Quite apart from witless social prejudices of that kind, the very machinery proposed for attaining the results desired has often no basis at all in scientific knowledge. Yet in this field some of our highest hopes for man's future may still reside. We have evidence already that the knowledge we have gained of the laws and machinery of inheritance in the lower animals holds good for man. Small beginnings are being made already by the studies

* Friday evening discourse delivered at the Royal Institution on May 27.

No. 3275 , VoL. 130] of selected pedigrees, the use of probability laws, the examination of correlations between characters either directly observable or detectable by refined methods of blood examination-all these give grow. ing hopes of our being able to map out the distribution of factors in the human chromosomes, those minute carriers of inheritance in the parent cells. Medical knowledge has a leading part to play here, for the most hopeful clues now in sight depend upon closer medical study of the inheritance of disease and abnormalities in family history. We are in practice cut off from the method of experimental mating in the study of human inheritance, and must perforce use the methods of medical observation and analysis of pedigrees. The work in sight is vast and may occupy many generations. All the more important then that it should begin early. There is no short cut to the power for human welfare that we may hope some day to gain by genetic knowledge. The only road to this has to be cleared up by persistent effort in this primary branch of medical research.

The other side of the study of the development of man's body, that of nurture, lies in the field of nutrition, and here there is a very different story. This study is concerned in part with the quantitative study of the energy requirements of the body and in part with the qualitative values of diet. It has only been a branch of exact science for the last generation or two. Our knowledge upon the qualitative side, even of the very existence of the vitamins, so familiar by name now to all, belongs only to the last twenty years. Yet from the knowledge so far won in this field we have already gained practical powers of high value. I will return presently to this subject of nutrition to illustrate in more detail the value and interest of this part of the medical field.

Pursuing our definition, we now come, after dealing with the development of the body, to the problems of its right use-and its right use in all conditions of activity and environment. Here we deal with problems of personal hygiene, of sleep, of diet in relation to climate and to bodily activity. We have to deal also with an intricate group of problems belonging to industrial life. The industrial revolution and the introduction of machinery upon a great scale brought a host of new problems under this head. Individual craftsmen throughout the ages have found for themselves their own ways of working to the best effect, and of making the compromises needed for gaining the best output with the least fatigue and damage to health. The intro. duction of machinery and the gathering of workers into large factories came about with far too much regard to the welfare of the machinery and the magnitude of its output, and with far too little regard to the machinery of the bodies of the workers. The application of physiological knowledge in this field has been lamentably slow in coming. Most of the elementary problems of maintaining efficiency 
in work and of the spells of rest needed for particular occupations of many kinds have been studied only within the present generation, after almost a century of waste, discomfort, and misery.

The War brought home to us our ignorance of this branch of medical study, though no other country had greater incentive, both in duty and in profit, to lead the way in its development. When the safety of our people depended upon the fullest output of war material and the maintained efficiency of the workers, it was found that we were ignorant, as a nation, of some of the most elementary laws of industrial health. We had to find and apply as best we could the optimum hours of work and the best use of rest pauses for different kinds of work, ranging from heavy physical labour to light manipulative tasks involving maintained attention to rapid machine processes. When the lives of men, or indeed of armies, might depend upon the rapid use of the spade in trench-warfare, it was found that nobody since Adam first used a spade had worked out the optimum rest-pauses for the best performance of a gang of digging men over different periods. Medical research had also to find new safeguards for men living in submarines below the sea, mining far into the earth, or flying to great heights in the air.

During and since the War, a great volume of research work has been done under the Industrial Health Research Board to clear up these problems connected with the right use of the human body. They deal with hours of work, heavy or light, rest pauses, shift systems, the problems of monotony in repetitive work; they have dealt with the human factor in the causation of accidents, with problems of ventilation, of lighting and heating, with all the special problems of vocational guidance and selection, with the study of body movements, posture, and physique in particular industrial processes, as well as with the special dangers arising from poisonous materials in particular trades or occupations.

We now come to the protection of the body from disease, and here we come for the first time to what is ordinarily thought of as medical work in its narrow sense. This part of the work falls, of course, at once under two main divisions. There is the work of preventing disease, and there is the work of curing or palliating disease when already present.

We can scarcely think, and have no reason to think, of disease as being caused otherwise than in one of three ways. There are diseases due to abnormalities of structure or chemical behaviour which are inherited and come from the genetic history of the individual. There are other diseases which are due to faults in the immediate environment of the body, early or late in its development, such as those, for example, known to be the result of imperfect nutrition. Lastly, there is a great variety of disease due to the direct attack upon the body by other forms of life in the shape of parasitic enemies.

We can aim at preventing inherited disease by increasing our knowledge of genetics and by regulating human mating. It will be very long before we have knowledge enough to gain much power in this direction, and how far we can use it when gained will depend upon our political structure and social habits. Already our genetic knowledge is enough to allow us to abolish at once one type of juvenile idiocy and greatly reduce other mental defects by regulation of marriages in the families displaying them.

Many diseases of environment are under our potential control already. Diseases like scurvy, beriberi, rickets, pellagra, are due to deficiencies of particular vitamins in the food. No doubt other abnormalities of body, including forms of mental weakness, will be found to be due to similar deficiencies, either in childhood or during embryonic life, and we know already, though not yet in enough detail, that deficiencies in diet diminish the resistance of the body to infective disease.

Lastly, we come to the great welter of disorders produced by the actual presence within the body of enemy parasites. These may be multicellular aninals such as parasitic worms, unicellular forms such as the trypanosome of sleeping sickness, or the plasmodium of malaria ; they may be bacteria, as in the infections of typhoid fever and pneumonia, or they may be minute bodies, barely visible by ordinary microscopes, which are the so-called 'viruses' causing diseases such as smallpox, measles, yellow fever, and so on. You have heard much of the great labours that have gone so far in giving us control over these enemies of our race, whether in tropical climates or at home. The work has involved clinical study of the diseases, intensive detective work to find out how the parasites are conveyed, whether by water, air, or soil, or by the intricate participation of insects and other carrying hosts. The study of these hosts and of the parasites themselves has been the work of zoologists in the field and in the laboratory, while the study of bacteria is a science by itself, with its specialised technical methods.

It is well known also that the knowledge gained here has already given us great powers in the prevention of disease, and an important part of the medical profession is devoted to their use in administration. I would only note here how random seems to be the relation of knowledge to power within this complex field. A very little knowledge of the infective agent concerned may give almost complete powers of prevention. We have the full power of preventing smallpox in any given man, or of distemper in any given dog, yet know much less about the nature of those viruses than about that of any other of the groups I have named. In malaria, on the other hand, we have a great deal of knowledge about the life history of the parasite and its mode of conveyance by the mosquito from man to man. We have the power of freeing any given community from the disease, but only if we have money enough to break the chain of events by getting rid of the mosquito carrier. We had this knowledge and this power a generation ago, yet there is more malaria in the world now than then, and it afflicts with its curse probably a third of the whole human race, with a death-rate of two million persons every year. What is needed now 
is still more intensive research work that will allow us a more ingenious attack upon the parasite by methods which it may be practicable to use upon an immense scale at reasonable cost.

So much for preventive research. But protection from disease involves also its curative or palliative treatment; and here we come, for the first time, to the work of the medical profession as ordinarily understood, whether that of the physician or of the surgeon. When disease is beginning or has been established, the doctor is concerned to give his help in the most effective way to the single individual before him. This offers him an intricate set of problems which make his work a special branch of applied science in which high arts of skill are based upon the knowledge available. He cannot act effectively until he has found not only the nature of the disorder present but also its particular manifestations in that individual case. The very fact that he must avoid opening the body to look inside it has led to the development of intricate devices for observing and deducing the actual facts from the outside. I need not dwell upon the skill needed by the competent physician, nor upon the manipulative wonders now made possible to the surgeon by Lister's work: nor, again, need I do more than point to the high responsibilities undertaken by the physician or surgeon to whom a human life is entrusted. At every point their knowledge and skill depend upon the results of research work of many kinds, and their powers can only advance as research work progresses.

Lastly, there remains to consider, in the definition I am following, the protection of the body from accident, and its repair. The study of accidents has led to much profitable research work, of which some of the chief has been done under the Industrial Health Research Board. Accidents can be sorted out into those due to the unfitness of particular workers for given tasks, or to states of mind, or to conditions of fatigue and other states of the body, or, again, to the absence of proper protective devices and administrative rules. When their causation is accurately found, preventive work is at once rightly guided.

Under this last head, too, there is the skilled work of the surgeon in repairing physical damage done to the body. But we can only point to this here as completing our rapid survey of the whole campaign in the medical field. It is worthy of note that in coming to the end of this general story, we find ourselves close to the beginning of it again. Surgery has brought us near to the study of heredity again with which we started. For uncounted centuries the surgeon has repaired so far as possible the injuries of man's body in warfare and accident, and his chief concern has always been at least to prevent death by loss of blood. There is no more ancient surgical problem than that of whether a healthy man can lend some of his blood to save the life of another. Nearly three hundred years ago Dr. Lower of Oxford showed to King Charles II. and the early Royal Society that one dog's blood might be transfused into another dog to replace its own. But it has only been in the last twenty years that we have learned why it is that, while the blood of one man given to a patient who has suffered loss by bleeding may be fatal, that of another man may have no ill-effects and may restore life--and happily that knowledge came in time to save many thousands of lives in the War. Careful laboratory studies have shown that every human being belongs to one of four groups, distinguished by the different precipitating powers of their bloods, one against another. These subtle blood differences, far more subtle than any chemical analysis could detect, are of daily importance in surgery. They play a part also now in the study of human inheritance with which we began this survey.

$$
\text { (To be continued.) }
$$

\section{Oriental Studies in the University of Chicago*}

I $\mathrm{N}$ the past ten years the United States have made remarkable advances in archæological research in both the New World and the Old. In America itself the whole range of continental civilisation in one form or another from Alaska to Peru has been brought under investigation by university departments and public or semi-public institutions. In particular, the activities of the Carnegie Institution of Washington in Central America and of the Smithsonian Institution in the south-western United States have contributed materially to the advancement of archæological science through the intensive studies by means of which they are gradually filling in details of the chronological sequence in the development of culture in these areas.

In the Old World, both independently and in cooperation with European scientific bodies, American

* The Oriental Institute of the University of Chicago: in Commemoration of the Dedication of the Oriental Institute Building, Dec. 5, 1931. Pp. iv +68 . 25 cents. archæologists have extended their activities over a wide area. The American Schools in France, Athens, and Jerusalem and the expedition of the University of Pennyslvania, in conjunction with the British Museum, at Ur have achieved results of signal importance in the investigation of the history of man and his early civilisation. Less widely known, perhaps, but not of less moment, are the operations of the Oriental Institute of the University of Chicago, of which some account is given in a recent publication issued in commemoration of the opening of new buildings.

When the Oriental Institute was created by the trustees of the University of Chicago and organised by Dr. J. H. Breasted in 1919, its aim was to become " a research laboratory for the investigation of the early human career", and to trace "the course of human development from the merely physical man disclosed by the palæontologist to the rise and advance of civilised societies, the product of social and material evolution culminating in

No. 3275 , VoL. 130] 